\title{
Metropolização no Sudeste Brasileiro: A perigosa convivência com áreas contaminadas no processo de industrialização
}

Metropolises in Southeastern Brazil: Dangerous living with contaminated areas in the industrialization process

Metrópolis en el sureste de Brasil: salón peligrosa con áreas contaminadas en el proceso de industrialización

Ricardo Alexandre da Silva Doutorando, PósUrb - PUCCampinas, Brasil. ricardosilvaarq@gmail.com

Laura Machado de Mello Bueno Professora Doutora, PósUrb - PUCCampinas, Brasil. laurabueno500@gmail.com 


\section{RESUMO}

As fontes de contaminação estão articuladas às estruturas produtivas, comerciais, serviços e residuais situadas em áreas urbanas e rurais. Os contaminantes prejudicam o solo, as águas e causam riscos de danos à população e aos bens situados no entorno, no tecido urbano e nos processos de urbanização do território. Muitas destas áreas são regulares e irregulares, públicas ou particulares. Os Postos de Combustíveis, Lixões, antigas indústrias e outras fontes de contaminação, estão no território urbano e rural e geram problemas socioambientais. Este artigo analisa a distribuição tipológica e locacional, face ao crescente número de áreas contaminadas registradas nos municípios da Região Metropolitana de Campinas - RMC/SP, em paralelo aos atributos ambientais e à sua importância no contexto regional. A RMC, com 3.094,181 habitantes e área de 3.840,648 km², a noroeste da capital, possuía em 2013, 384 áreas contaminadas, sendo 93 destas no município de Campinas, sede da RMC. Através do detalhamento de casos de contaminação no espaço intraurbano de Campinas - Postos de Combustíveis em área urbana consolidada, o "Lixão da Pirelli" de iniciativa municipal, e empreendimentos habitacionais de médio e alto padrão construídos em antigo depósito de rejeitos industriais - o artigo apresenta os problemas na escala do urbanismo, relacionando-os ao processo de planejamento e gestão. Discute-se a falta de medidas preventivas e corretivas pela municipalidade.

PALAVRAS-CHAVE: gestão urbana, conflitos socioambientais, políticas públicas ambientais.

\section{ABSTRACT}

The contamination sources are articulated to production structures, trade, services and waste located in urban and rural areas. Contaminants harm the soil, the water and cause risk of damage to people and property located in the surroundings of the urban fabric and the territory urbanization processes. Many of these areas are regular and irregular, public or private. The petrol stations, dumps, old industries and other sources of contamination are in urban and rural areas and generate social and environmental problems. This article analyzes the typological and locational distribution, given the growing number of contaminated sites registered in the Metropolitan Region of Campinas - MRC/SP, in parallel with environmental attributes and their importance in the regional context. The MRC, with 3.094,181 habitants and an area of 3840.648 square kilometers, northwest of the capital, held in 2013, 384 contaminated areas, 93 of these in the city of Campinas, the MRC headquarters. Through the detail of contamination cases in intra-urban area of Campinas - Fuel Stations in consolidated urban area, "Lixão da Pirelli" municipal initiative, and housing projects of medium and high standard built in ancient deposit of industrial waste the paper presents problems in urban scale, linking them to the planning and management process. Discusses the lack of preventive and corrective measures by the municipality

KEY-WORDS: urban management, environmental conflicts, environmental policy

\section{RESUMEN}

Las fuentes de contaminación son articulados a las estructuras de producción, el comercio, los servicios y los residuos situados en las zonas urbanas y rurales. Los contaminantes dañan el suelo, el agua y el riesgo causa de daños a personas y bienes situados en los alrededores del tejido urbano y los procesos de urbanización del territorio. Muchas de estas áreas son regulares e irregulares, pública o privada. Las gasolineras, vertederos, las viejas industrias y otras fuentes de contaminación se encuentran en zonas urbanas y rurales, y generan problemas sociales y ambientales. En este artículo se analiza la distribución tipológica y de localización, dado el creciente número de sitios contaminados registrados en la Región Metropolitana de Campinas - RMC/SP, en paralelo con los atributos ambientales y su importancia en el contexto regional. La RMC, 3.094,181 habitantes y una superficie de 3840.648 kilómetros cuadrados, al noroeste de la capital, que tuvo lugar en el año 2013, 384 áreas contaminadas, 93 de ellos en la ciudad de Campinas, la sede del MRC. A través de los detalles de los casos de contaminación en la zona intraurbana de Campinas - Estaciones de combustible en zona urbana consolidada, "Lixão da Pirelli" iniciativa municipal, y los proyectos de viviendas de medio y alto nivel construido en la antigua depósito de residuos industriales - los regalos de papel problemas de escala urbana, vinculándolos al proceso de planificación y gestión. Se analiza la falta de medidas preventivas y correctivas por parte del município

PALABRAS CLAVE: la gestión urbana, conflictos ambientales, la política pública ambiental. 


\section{COLOCAÇÃO DO PROBLEMA: A URBANIZAÇÃO FRAGMENTADA CONTEMPORÂNEA E AS ÁREAS CONTAMINADAS}

Atualmente em todo o mundo, os problemas decorrentes da industrialização, como a poluição e contaminação da água, solo e atmosfera, aliados à questão da produção do ambiente, de compostos e seus resíduos, tem gerado debates cada vez mais acentuados. A industrialização eletromecânica e metalúrgica de bens de consumo duráveis, e com base no uso do petróleo, desenvolveu-se tardiamente nos países do capitalismo periférico, como o Brasil. As chamadas indústrias de base, implementadas pelo Estado, apresentavam práticas (correntes à época) pouco preocupadas com impactos ambientais. Nos anos 1950 iniciou-se a industrialização indústria automotiva, química, etc - apoiada no capital multinacional disseminando-se notadamente nas maiores capitais (SINGER, 1973). Devido à transferência de tecnologias e procedimentos industriais já em questionamento nos países de origem e ao ambiente institucional de pouca regulação, como o brasileiro, à época esse processo resultou em grande número de áreas contaminadas.

O solo é inegavelmente um dos elementos naturais que mais se tornam comprometidos e, por seus atributos pedológicos, é um dos que apresentam mais rapidamente as influências das atividades humanas, em geral negativas, pela compactação mecânica promovida pela diminuição da porosidade dos agregados com efeitos diversos sobre o meio: menor infiltração e menor capacidade de armazenamento de água, maior escoamento superficial e outros ${ }^{1}$.

Em paralelo a discussão, tem-se a questão da poluição, que é apresentada como um problema da sociedade contemporânea. Porém, Acselrad (2006:119) afirma que "a poluição não é um problema, é um produto não vendável", que é socialmente compartilhada. A poluição é um produto do processo industrial, é um necessário subproduto das atividades de produção das mercadorias vendáveis. Assim, não é um problema da sociedade, mas é sim intrínseco à própria atividade industrial. Entretanto, a regulação proposta historicamente pelo Estado, tendeu a tratar a poluição como um problema da sociedade, internalizando para a sociedade e para o fundo público o tratamento de suas consequências.

Durante décadas o solo foi o local preferencial para a alocação destes produtos, com base numa suposta capacidade de autodepuração do solo. Tal conceito era compartilhado pela ciência, que apoiava a simples disposição de resíduos domésticos e industriais já que a capacidade de recuperação seria infindável, dado que o ambiente possuiria capacidades de transformar estes produtos em elementos inofensivos aos seres humanos e ao ambiente natural. Os resíduos de atividades industriais e domésticas, assim como os combustíveis

\footnotetext{
${ }^{1} \mathrm{O}$ solo é composto por aglomerados formados por fragmentos de rocha microagregadas, areia; silte; e argila, originados a partir de ações ígneas; magmáticas, e da ação do meio natural, ventos e chuvas, que exercem ações cimentares como, componentes microorgânicos e de matéria orgânica humificada e seus constituintes. (SOARES, 2001).
} 
voltados aos sistemas de energia e transporte, são preocupantes por suas características e também pela forma de como estão acondicionados.

Os combustíveis automotivos têm contribuído para este importante quadro de contaminação do solo já que sua armazenagem é realizada através de tanques subterrâneos, que tem mostrado ser uma relevante fonte de contaminação e poluição ambiental, afetando a qualidade do solo e principalmente das águas subterrâneas ${ }^{2}$. Além de serem muito danosos ao meio ambiente, sua ocorrência mais frequente se dá em áreas urbanas ou em expansão, como será mostrado adiante. A presença de uma área contaminada pode ocasionar danos a saúde humana, comprometimento da qualidade do sistema hídrico, do solo e ao tecido urbano, em edificações e ao meio ambiente (MOTA, 1999; RODRIGUES, 1998). As preocupações relacionam-se especialmente aos riscos associados a esses eventos, como a segurança pública, saúde da população e possíveis danos ao solo e águas subterrâneas, comprometendo a qualidade dos mananciais para o abastecimento público (BUENO, 2008).

Os efeitos da contaminação, na grande maioria dos casos, extravasam os limites do lote e podem ser percebidos até mesmo na forma de afloramento do produto em galerias de esgoto, redes de drenagem de águas pluviais, no subsolo de edifícios, em tuneis, escavações e poços de abastecimento de água. As cidades, densamente povoadas, tem visto o aumento destas ocorrências e dos seus efeitos em estruturas subterrâneas; como os sistemas subterrâneos públicos de águas pluviais, esgoto, telefonia, metrô, eletrificação, subsolo de edificações, garagens, escavações, poços d'água, entre outros. Os maus odores, os gases tóxicos e inflamáveis afetam os espaços públicos e causam acidentes com perdas humanas e materiais (CETESB, 2016).

\section{OBJETIVOS}

\section{1 - O TRATAMENTO DAS ÁREAS CONTAMINADAS NO ESTADO DE SÃO PAULO}

A questão da contaminação do solo e das águas subterrâneas já é objeto de grande preocupação e definição de políticas públicas nas últimas cinco décadas (principalmente a partir dos anos 1960) em países da Europa e América do Norte (TROVÃO, 2006). No Brasil as preocupações e ações são mais recentes. Esse problema tem adquirido importantes proporções em grandes centros urbanos, principalmente nas áreas metropolitanas e distritos industriais antigos. Destacam-se a região do $A B C$ e a região sul de São Paulo, na RMSP, o Porto de Santos, Cubatão, no ESP, além do Rio de Janeiro, o Porto do Rio de Janeiro e Baixada Fluminense (BRANCO, 1984; GUIBERLET, 1996; ACSELRAD, 2006). Desde 2002 o Governo do Estado de São Paulo (ESP), por meio da Companhia de Tecnologia de Saneamento Ambiental

\footnotetext{
${ }^{2}$ A ação dos contaminantes está diretamente relacionada a solos com poros com diversos diâmetros e capilaridades. O contaminante acondicionado e retido nas cavidades de um tipo de solo, comporta-se com diâmetros e em diferentes pontos de saturação, e sob a ação das águas pluviais, rompe a força capilar acumulandose de forma saturada e não mais em água, atingindo o meio hídrico subterrâneo ampliando sua área de influência. (TROVÃO, 2006).
} 
(CETESB) divulga listas de áreas comprovadamente contaminadas por produtos químicos por empresas poluentes. O cadastro, pioneiro no Brasil (INEA, 2016), é decorrência de acidentes recentes, quando se percebeu que as causas decorriam de atividades impactantes antigas, anteriores à legislação ambiental brasileira de 1981. Para a execução deste levantamento, a CETESB teve como suporte técnico e financeiro a participação da GIZ - Deutsche Gesellschaft für Internationale Zusammenarbeit (entidade alemã de cooperação internacional), após detectar a ocorrência de explosões e contaminação de trabalhadores em empreendimentos imobiliários em áreas industriais desativadas no Estado de São Paulo. Desde então a CETESB tem procedimentos constantes de identificação de casos, avaliação de risco e contaminação, projetos de remediação e recuperação (SILVA, 2013: 83). Em números absolutos, as áreas comprovadamente contaminadas cadastradas no ESP, passaram de 257, em 2002, para 4771 em 2013. A expansão da urbanização em todo o Estado alcançou em muitos casos, áreas antes rurais utilizadas para despejo de contaminantes, fazendo com que o poder público se debruçasse sobre o problema. $O$ crescimento anual se deve à percepção, tanto dos técnicos, quanto da sociedade sobre os problemas ambientais e maior mobilização e denúncias. Em decorrência de estudos internos e denúncias, a CETESB visita e avalia os locais com atividades econômicas ativas e ou inativas, registrando o novo caso no Cadastro.

Tabela 1: Áreas contaminadas no Estado de São Paulo

\begin{tabular}{lcccccc}
\hline \multicolumn{7}{c}{ Atividade } \\
\hline Região & Comercial & Industrial & Resíduos & $\begin{array}{c}\text { Posto de } \\
\text { Combustíveis }\end{array}$ & $\begin{array}{c}\text { Acidentes/Desconhecida/ } \\
\text { Agricultura }\end{array}$ & Total \\
São Paulo & 76 & 248 & 38 & 1.294 & 09 & 1.665 \\
RMSP - outros & 48 & 199 & 23 & 535 & 11 & 816 \\
Interior & 75 & 228 & 45 & 1.314 & 15 & 02 \\
Litoral & 29 & 42 & 28 & 247 & 01 & 348 \\
Vale do Paraíba & 04 & 51 & 02 & 207 & 38 & 265 \\
\hline Total & 232 & 768 & 136 & 3.597 & 4.771 \\
\hline \multicolumn{7}{r}{}
\end{tabular}

Fonte: CETESB, 2013

A distribuição espacial (Tabela 1) reflete a própria história da industrialização paulista - $52 \%$ dos locais estão na Região Metropolitana de São Paulo (RMSP), sendo 35 \% na capital. 0 interior do Estado, somando-se litoral e Vale do Paraíba, soma 2290 áreas. A maioria é composta por Postos de Combustíveis (CETESB, 2013), localizados geralmente no espaço intraurbano. É frágil o controle do comportamento deste setor sobre os modos de transporte e acondicionamento de combustíveis, bem como manutenção periódica dos tanques (CETESB, 2013). A Legislação federal ${ }^{3}$ que regula a implantação e licenças periódicas de postos no meio urbano foi criada somente a partir de 2000, e no Estado de São Paulo há um decreto de 1994.

\footnotetext{
${ }^{3}$ As resoluções CONAMA 273/2000, 319/2002 e 362/2005, as portarias da ANP de 1999 e 2000, assim como normas do INMETRO.
} 
Além de postos de gasolina, as atividades que mais contaminam as áreas urbanas são as indústrias - 768 (16\%, metade dos casos na RMSP), empresas de comércio/serviços - 232 (5\%), depósitos de resíduos - 136 (3\%), além dos acidentes. Nesta questão as deficiências são gritantes, como a falta de um manejo seguro, aliado a falhas e vazamentos no transporte viário, por dutos e ou armazenamento, encarados apenas como erros casuais, sem avaliação prévia das consequências ao meio urbano local e ao meio ambiente.

\section{ASPECTOS METODOLÓGICOS}

Está dentro de uma pesquisa mais ampla, onde muitas destas áreas contaminadas estão vinculadas as atividades industriais em rede regional em várias escalas. Numa primeira, é realizado um levantamento de casos presentes no território metropolitano, a partir dos municípios mais industrializados e com maior número de áreas contaminadas. Numa segunda etapa, munido do município com maior número de áreas contaminadas, é realizada uma seleção das áreas mais especificas, considerando o posicionamento no espaço urbano e rural. Numa terceira etapa, para estas áreas, são analisados os atributos tipológicos, urbanísticos e os usos permitidos pelo município e os potenciais danos a ao solo, água ou estruturas edificadas.

\section{RESULTADOS}

\section{1. ÁREAS CONTAMINADAS ANTIGAS NA JOVEM REGIÃO METROPOLITANA DE CAMPINAS}

A RMC ${ }^{4}$ é composta por 20 municípios e tem uma população de $3.094,181$ habitantes, ou 6,8\% do total estadual (93,20\%). Apresenta cinco municípios com população superior a 200.000 habitantes: Campinas (1.164,098 hab.), Sumaré (265.955 hab.), Indaiatuba (231.033 hab.), Americana (229.322 hab.) e Hortolândia (215.819 hab.). Três municípios (Santa Barbara d'Oeste, Valinhos e Itatiba) possuem população entre 100.000 e 200.000 habitantes, outros quatro entre 50.000 e 100.000 habitantes, e oito entre 10.000 e 50.000 habitantes. O PIB per capita da RMC (R\$37.183,64) é superior ao estadual ( $R \$ 32.454,91)$ e o nacional (R\$ 31.506,83). Dentre os municípios da RMC, Paulínia possui o maior PIB per capita regional (R\$ 99.172,47), seguido de Vinhedo (R\$ 71.364,01), Jaguariúna ( $R \$ 48.351,78$ ) e Holambra (R\$ 43.810,19). O município de Campinas ( $\mathrm{R} \$ 33.939,56$ ) possui um PIB per capita um pouco abaixo da média da RMC e, Morungaba (R\$ 15.996,84) e Artur Nogueira (R\$ 12.278,51), possuem os menores PIBs per capita numa região que apresenta importantes disparidades espaciais, sociais e de renda em suas periferias. (BAENINGER, 2001 e IBGE, 2013). A Tabela 3 apresenta o número das áreas contaminadas nos municípios da RMC desde 2002, distribuídas pelos municípios.

\footnotetext{
4 A Região Metropolitana de Campinas foi criada pela lei complementar estadual 870/2000. http://www.seade.gov.br/. Acessado em 30 julho de 2016.
} 
Tabela 2 - Áreas contaminadas na Região Metropolitana de Campinas - RMC

\begin{tabular}{|c|c|c|c|c|c|c|c|c|c|c|c|c|c|}
\hline Títulos & & & & Númer & de ár & as Cont & minad & -2002 & 2013 & & & & \\
\hline $\begin{array}{l}\text { Municípios } \\
\text { da RMC }\end{array}$ & 2002 & 2003 & 2004 & 2005 & 2006 & 2007 & 2008 & 2009 & 2010 & 2011 & 2012 & 2013 & $\begin{array}{c}\text { Tota } \\
\text { I }\end{array}$ \\
\hline Americana & - & 01 & 05 & - & 01 & 01 & - & - & 03 & 09 & 03 & - & 23 \\
\hline $\begin{array}{l}\text { Artur } \\
\text { Nogueira }\end{array}$ & - & 01 & - & 01 & - & - & - & - & 01 & - & 02 & 01 & 06 \\
\hline Campinas & 07 & 03 & 23 & 12 & 01 & 40 & 06 & 08 & 11 & 09 & 10 & 03 & 133 \\
\hline Cosmópolis & 01 & - & 01 & 01 & - & 04 & - & - & - & 02 & - & - & 09 \\
\hline $\begin{array}{l}\text { Engenheiro } \\
\text { Coelho }\end{array}$ & - & 01 & - & - & - & - & - & - & - & - & - & - & 01 \\
\hline Holambra & - & - & - & - & - & 01 & - & 01 & - & - & - & 01 & 03 \\
\hline Hortolândia & - & - & 02 & - & - & 02 & - & - & 02 & 05 & 01 & 01 & 13 \\
\hline Indaiatuba & 01 & - & 01 & - & 01 & 01 & - & - & 09 & 02 & 01 & - & 16 \\
\hline Itatiba & 01 & - & 08 & - & - & - & 02 & 04 & 05 & 01 & 02 & 01 & 24 \\
\hline Jaguariúna & - & - & - & 02 & - & - & - & 03 & 01 & 02 & 01 & - & 09 \\
\hline Monte Mor & 01 & - & - & - & - & - & - & 01 & - & - & - & - & 02 \\
\hline Morungaba & - & - & - & - & - & - & - & - & - & - & - & - & - \\
\hline $\begin{array}{l}\text { Nova } \\
\text { Odessa }\end{array}$ & - & - & - & - & 01 & - & - & 01 & - & - & 01 & - & 03 \\
\hline Paulínia & 06 & 07 & 12 & 02 & - & 04 & 05 & 09 & 03 & 13 & 04 & - & 65 \\
\hline Pedreira & - & - & 03 & 01 & 02 & 02 & 01 & - & - & 01 & - & 01 & 11 \\
\hline $\begin{array}{l}\text { Santa } \\
\text { Barbara } \\
\text { d'Oeste }\end{array}$ & - & 01 & - & 01 & 01 & 01 & 01 & 01 & 021 & 07 & - & - & 14 \\
\hline $\begin{array}{l}\text { Santo } \\
\text { Antônio de } \\
\text { posse }\end{array}$ & 02 & - & 01 & - & - & - & - & - & - & - & - & - & 03 \\
\hline Sumaré & 03 & 01 & 01 & 02 & - & 03 & 01 & - & - & 06 & 04 & 03 & 24 \\
\hline Valinhos & 01 & 01 & 03 & 02 & - & 01 & 01 & 01 & 03 & - & 01 & 02 & 16 \\
\hline Vinhedo & - & - & - & 02 & - & 01 & 01 & - & 04 & - & - & 01 & 09 \\
\hline Total & 23 & 16 & 60 & 26 & 07 & 61 & 18 & 29 & 43 & 48 & 30 & 14 & 384 \\
\hline Anual \% & - & 69,56 & 375 & 43,3 & 26,9 & 871,4 & 29,5 & 161,1 & 148,2 & 111,6 & 62,5 & 46,6 & - \\
\hline
\end{tabular}

Fonte: elaboração do autor sobre dados da CETESB, 2013.

Em comum, tiveram como processo de industrialização as intensas transformações geradas pelo processo de interiorização paulista a partir de Campinas, entre as décadas de 1950 e 1970. O interno, correspondente ao aglomerado urbano, que estabeleceu uma base industrial expressiva, dinâmica e compartilhada, e áreas conflitantes entre moradia, indústria e passivos ambientais oriundos de antigas fontes de contaminação ativas ou desativadas. Na RMC atualmente existem 384 áreas contaminadas cadastradas. Na linha final calculou-se o crescimento relativo ano a ano, da identificação das áreas. Destaca-se que de 2003 para 2004, foram identificadas na RMC 60 áreas, um acréscimo de 375\%. Também se destaca 2007 com identificação de 61 novas áreas, $871,4 \%$ de crescimento. Em relação a 2004, as áreas contaminadas tiveram o acréscimo de 44 áreas entre 2003/2004. Já ao considerar o ano de 
2007, mais 54 áreas foram detectadas entre 2006/2007. Diferentemente do município de São Paulo e da RMSP (Tabela 2), onde os postos de gasolina são a grande maioria das áreas contaminadas, na RMC o número de postos e de indústrias com problemas é semelhante. A Tabela 4 abaixo apresenta os ramos de atividade que causaram a contaminação nos municípios da RMC.

Tabela 3 - Relação de Ramos de Atividade e Áreas Contaminadas

\begin{tabular}{|c|c|c|c|c|c|c|c|c|}
\hline \multirow[t]{2}{*}{ Municípios da RMC } & \multicolumn{5}{|c|}{ Ramos de Atividade } & \multirow{2}{*}{$\begin{array}{c}\text { Total de } \\
\text { Áreas } \\
\text { Contamin. }\end{array}$} & \multirow{2}{*}{$\begin{array}{c}\text { Pop. } \\
\text { (mil/hab.) } \\
2014\end{array}$} & \multirow{2}{*}{$\begin{array}{l}\text { Área } \\
\mathrm{Km}^{2}\end{array}$} \\
\hline & Posto & Indus. & $\begin{array}{l}\text { Com./ } \\
\text { Serv. }\end{array}$ & Resíd. & Agricult. & & & \\
\hline Americana & 18 & 04 & 01 & 01 & - & 23 & 226.970 & 133,35 \\
\hline Artur Nogueira & 06 & - & - & - & - & 06 & 49.346 & 177,752 \\
\hline Campinas & 93 & 28 & 06 & 06 & - & 133 & $1.154,617$ & 795,697 \\
\hline Cosmópolis & 04 & 04 & - & 01 & - & 09 & 65.628 & 795,697 \\
\hline Engenheiro Coelho & 01 & - & - & - & - & 01 & 18.153 & 109,798 \\
\hline Holambra & 03 & - & - & - & - & 03 & 13.046 & 64,2777 \\
\hline Hortolândia & 10 & 02 & - & 01 & - & 13 & 212.527 & 62,224 \\
\hline Indaiatuba & 04 & 09 & - & 01 & 01 & 15 & 226.602 & 310,564 \\
\hline Itatiba & 07 & 14 & 01 & - & - & 21 & 111.620 & 517,504 \\
\hline Jaguariúna & 02 & 07 & - & - & - & 09 & 50.719 & 142,437 \\
\hline Monte Mor & 01 & 01 & - & - & - & 02 & 54.462 & 240,787 \\
\hline Morungaba & - & - & - & - & - & - & 12.779 & 146,753 \\
\hline Nova Odessa & 01 & 02 & - & - & - & 03 & 56.008 & 73,298 \\
\hline Paulínia & 19 & 10 & 31 & 03 & 01 & 65 & 95.221 & 139,332 \\
\hline Pedreira & 01 & 08 & 01 & 01 & - & 11 & 45.052 & 109,71 \\
\hline Santa Barbara d'Oeste & 01 & 13 & - & - & - & 14 & 189.223 & 271,492 \\
\hline Santo Antônio de posse & 01 & 01 & - & 01 & - & 03 & 22.176 & 154,113 \\
\hline Sumaré & 06 & 16 & 02 & - & - & 24 & 262.308 & 153,303 \\
\hline Valinhos & 07 & 06 & - & 03 & - & 16 & 118.302 & 148,528 \\
\hline Vinhedo & 03 & 06 & - & - & - & 09 & 71.217 & 81,742 \\
\hline Total & 188 & 131 & 42 & 18 & 02 & 384 & $3.055,976$ & $3.840,6$ \\
\hline
\end{tabular}

Fonte: elaboração do autor sobre dados da CETESB, 2013.

A Tabela 3 apresenta a relação de municípios da RMC e os tipos de atividades econômicas, que possuem maior quantidade de locais contaminados. Em primeiro lugar destacam-se os Postos de Combustíveis, com 188 áreas; em segundo lugar Indústrias, com 131 áreas; em terceiro lugar, Na Comércio/Serviços com, 42 áreas; em quarto lugar, Resíduos, com 18 áreas e quinto lugar, Agricultura/Acidente/Desconhecida, com duas áreas ao todo. Os municípios, que apresentam o maior acréscimo de áreas contaminadas, são Campinas e Paulínia. Campinas, que tinha 23 áreas em 2002, teve um acréscimo de 17 áreas, atingindo 40 áreas em 2007. Em Paulínia, por outro lado, foram encontradas 12 áreas em 2004, mais 09 áreas em 2009 e mais 13 em 2011. Outros casos que se destacam são Sumaré, Americana e Santa Bárbara do Oeste, onde foram encontradas entre somente em 2010 respectivamente seis, nove e sete áreas 
contaminadas. Vê-se que os municípios da RMC apresentam locais contaminados em uma escala mais abrangente envolvendo produção, comercialização e distribuição dos produtos industriais. Isto se deve, a uma questão histórica que envolve a questão da circulação de pessoas, produtos, serviços e estruturação territorial. A identificação das áreas contaminadas, concentrando-se em anos específicos por município, denotam que, quando se identifica uma área contaminada, é comum que a pesquisa se amplie, revelando-se práticas semelhantes de contaminação em locais próximos.

Campinas é o município com maior número de áreas ao todo, ou seja, com 123 áreas, sendo que, 93 áreas correspondem a Postos de Combustíveis; Áreas Industriais, 28; sendo que Comércio/Serviços e Resíduos possuem a mesma quantidade - seis ao todo. Logo depois de Campinas, o município com o maior número de áreas contaminadas, é a cidade de Paulínia com 65 áreas ao todo, estas provenientes do ramo de Comércio/Serviços, com 31 áreas, seguido pelos Postos de Combustíveis, com 19 áreas e Indústria, com 10 áreas ao todo. Apesar da contribuição dos outros municípios, é notável que Paulínia $\left(139,332 \mathrm{~km}^{2}\right)$ um munícipio com área muito menor do que Campinas $\left(795,697 \mathrm{~km}^{2}\right)$, apresente uma incidência igual e ou maior em número de áreas contaminadas em relação ao município sede da RMC. O maior número de áreas contaminadas por comércio e serviço, ao invés de indústrias e ou postos de gasolina, decorre da proeminência do setor de comércio de derivados de petróleo, produzidos pela Refinaria do Planalto - REPLAN, inaugurada em 1972 (PETROBRÁS, 2016), para as grandes distribuidoras de combustíveis. Como centro nacional de produção e distribuição de combustíveis, a tendência é que as ocorrências de contaminações sejam concentradas na cadeia produtiva, entre refino, acondicionamento e distribuição. Além disto, estes pontos de contaminação estão localizados de maneira justaposta dentro da área de produção da REPLAN. Em Paulínia existem outros pontos, localizados nas imediações da refinaria, as margens do rio Atibaia, como a área da fábrica de pesticidas da Shell no bairro Recanto dos Pássaros ${ }^{5}$ e também na unidade fabril da Rhodia. Os outros municípios com expressivo número de áreas contaminadas cadastradas são: Sumaré, com seis áreas correspondentes a Postos de Combustível, 16 Indústrias e duas áreas de Comércio/Serviços, totalizando 24 áreas ao todo. Em seguida vem Americana, com 18 áreas de Postos de Combustível, quatro indústrias, uma área de Comercio/Serviços e uma área de Resíduos totalizando 23 áreas ao todo. Itatiba, com sete Postos de Combustível, 14 Indústrias e uma área de Comércio/Serviços, totalizando 21 áreas ao todo. Indaiatuba apresenta quatro Postos de Combustível, nove

\footnotetext{
${ }^{5}$ A Shell Química fabricou agrotóxicos em Paulínia entre 1975 e 1993, contaminando o lençol freático nas proximidades do rio Atibaia, com os organoclorados aldrin, endrin e dieldrin. Em 1994, a Shell prestes a vender a área à Cyanamid Química, foi analisada pela CETESB, que identificou uma rachadura numa piscina de contenção com a contaminação do freático, por dieldrin em índices 11 vezes superiores. A Prefeitura de Paulínia pediu ao laboratório da Unesp, exames de sangue em 156 pessoas, e 86\% dos moradores do apresentaram contaminação. Desses, 88 apresentam intoxicação crônica, 59 apresentavam tumores hepáticos e da tireóide e 72 estavam contaminados por drins. Das 50 crianças com até 15 anos avaliadas, 27 manifestavam um quadro de contaminação crônica. Após isto, a Justiça decretou à Shell indenizar e promover a remoção imediata de todos os moradores da área (REZENDE, 2005 e SUASSUNA, 2001).
} 
Indústrias, uma área de Resíduos e uma área contaminada a partir da agricultura/acidente/desconhecida, totalizando 16 áreas ao todo. Artur Nogueira e Engenheiro Coelho não apresentam um número significativo de áreas contaminadas devido ao perfil econômico de suas atividades produtivas, focadas na agricultura. É o ramo de comercio e serviços, representado pelos Postos Combustíveis (Artur Nogueira com seis e Engenheiro Coelho com um) que tem contribuído com a totalidade das áreas contaminadas. Ainda analisando, o grupo de cidades com perfil agrícola tem-se Morungaba, que não apresenta nenhuma área contaminada, provavelmente devido à implantação de Postos de Combustíveis mais recentes, com medidas e monitoramento adequados e melhor fiscalizados pela CETESB. Dentre o grupo de municípios com perfil agrícola, a exceção é o município de Santo Antônio de Posse. A Tabela 3 mostra apenas três áreas contaminadas, um posto de combustível, uma indústria e uma área contaminada por resíduos, o chamado Aterro Industrial Mantovani ${ }^{6}$, uma das maiores áreas contaminadas no Brasil.

\subsection{AS ÁREAS CONTAMINADAS VISTAS DE PERTO: ESPAÇO INTERURBANO DE CAMPINAS}

Dentro do contexto territorial regional, faz-se importante a compreensão do resultado e das implicações no espaço intraurbano, envolvendo as determinações da gestão municipal. A metodologia de análise multiescalar é pertinente para os estudos analíticos sobre as determinações que levam àquela situação, bem como a prospeç̧ão de visando a resolução dos problemas. Campinas município sede da Região Metropolitana, teve origem como um bairro emancipado de Jundiaí em 1797. No final do século XIX, o território campineiro originou novos desmembramentos com a criação do distrito de Valinho (atualmente município de Valinhos), pela Lei Provincial no 383 (28/05/1896). Rebouças, então Distrito de Paz de Campinas, originou Sumaré, através do Decreto no 14.334/1944. A Lei Estadual no 8092 (28/02/1964), emancipou de Campinas o município de Paulínia, e em 1969, inicia-se a construção e inauguração da REPLAN (Refinaria do Planalto, atualmente é nomeada como Refinaria de Paulínia) em 1972 com petróleo vindo da bacia de Campos e do Porto de São Sebastião. E pela Lei $n^{\circ} 7.664$ (30/12/1991) foi decretada a elevação do distrito de Hortolândia à condição de município desmembrado de Sumaré. (SILVA, 2013: 24).

Porém, a ideia de território ultrapassa a simples questão dos desmembramentos administrativos, atributos físicos ou naturais. Abarca relações entre indivíduos e empresas, numa organização complexa, contemplando os custos em circulações e comunicações. A ocupação do território de Campinas, numa visão regional dos agentes, buscou racionalizar a

\footnotetext{
${ }^{6}$ Localizado em área rural, iniciou suas atividades por volta de 1974, recebendo resíduos industriais e da reciclagem de óleos lubrificantes. Posteriormente, passou a receber outros tipos de resíduos industriais, ao lado do Centro de Resíduos Industriais - CETRIN. Segundo Braga (2009) mais de 50 indústrias despejaram mais de 500 mil toneladas de material tóxico e contaminantes, afetando a estrutura física, e a produção agrícola do entorno. Em setembro de 1987 as atividades são interrompidas pela CETESB devido a contaminação do solo e das águas subterrâneas por substâncias químicas, é um passivo ambiental com difícil minimização (CETESB, 2014).
} 
organização espacial segundo as necessidades industriais. A questão da acessibilidade é crucial para uma indústria, influencia desde a tomada de decisões, a escolha da localização, a articulação das circulações, determinando inclusive as tipologias espaciais dos aglomerados produtivos. Na análise das direções do crescimento da mancha urbana, a articulação entre as espacializações e a estrutura intraurbana ocorreu pela inserção regional da metrópole, direcionada à maior intensidade dos fluxos de transporte regional, rumando à cidade ou metrópole considerada. (SILVA, 2013: 23, 24 e 25; VILLAÇA, 1998).

A figura 2, mostra uma grande concentração de áreas contaminadas, composta por Postos de Combustíveis (amarelo), seguido por Indústrias (laranja) e Resíduos (roxo). A maior incidência de pontos contaminados de origem industrial ou resultante de acondicionamento irregular, corresponde as unidades situadas as margens da Rodovia Anhanguera, e também na Zona Industrial situada próximo ao Aeroporto de Viracopos próximo ao importante Rio Capivari. A maior parte destas áreas é formada por Postos de Combustíveis, localizados no espaço intraurbano consolidado, enquanto outras áreas estão dispersas pelos vetores de crescimento. Além disso, é perceptível o posicionamento de várias áreas contaminadas, junto aos eixos viários que conectam o município de Campinas aos municípios da RMC. Na Figura 2 são destacadas três localidades - A, B e C - objeto de análise mais detalhada de três situações típicas encontradas no espaço metropolitano: Postos de Combustíveis (A), Mansões Santo Antônio (B) e Lixão da Pirelli (C) conforme segue abaixo: 


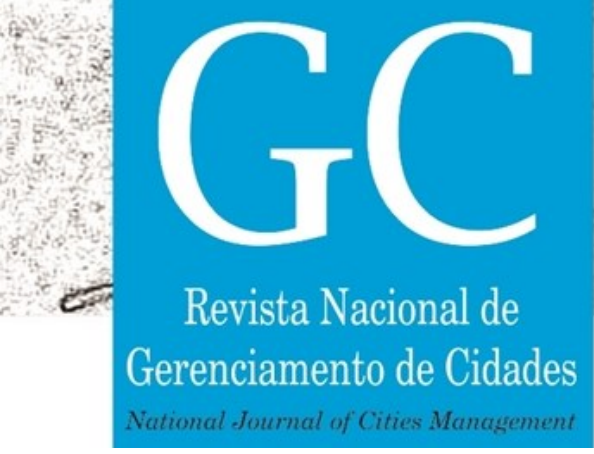

Figura 2. Localização das áreas contaminadas no perímetro urbano de Campinas

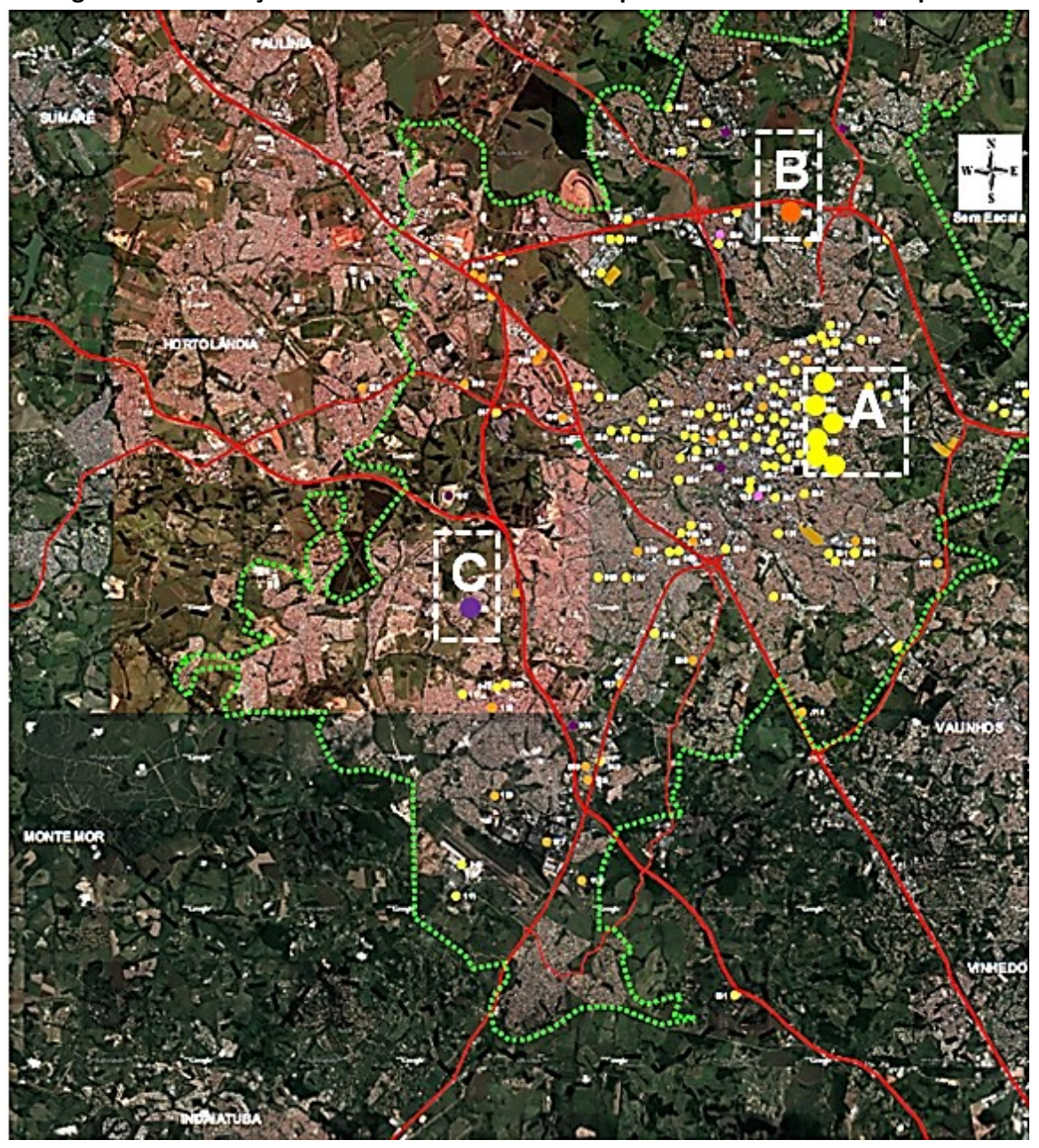

Legenda: Postos de Combustiveis $\square$ Indüstria $\square$ Residuos $\square$ Comércio

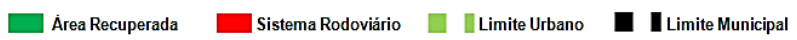

[A-]

Fonte: Elaboração do autor sobre imagem do Goggle Earth. Dados da CETESB, 2013

A Figura 3 destaca os Postos de Combustíveis na área A, situados ao longo da Avenida NorteSul, importante eixo viário de Campinas, implantado ao longo do córrego dos Anhumas canalizado. Segundo o Cadastro da CETESB, dois deles já constam como área contaminada há 10 anos, enquanto o restante está cadastrado há sete, seis e dois anos. 


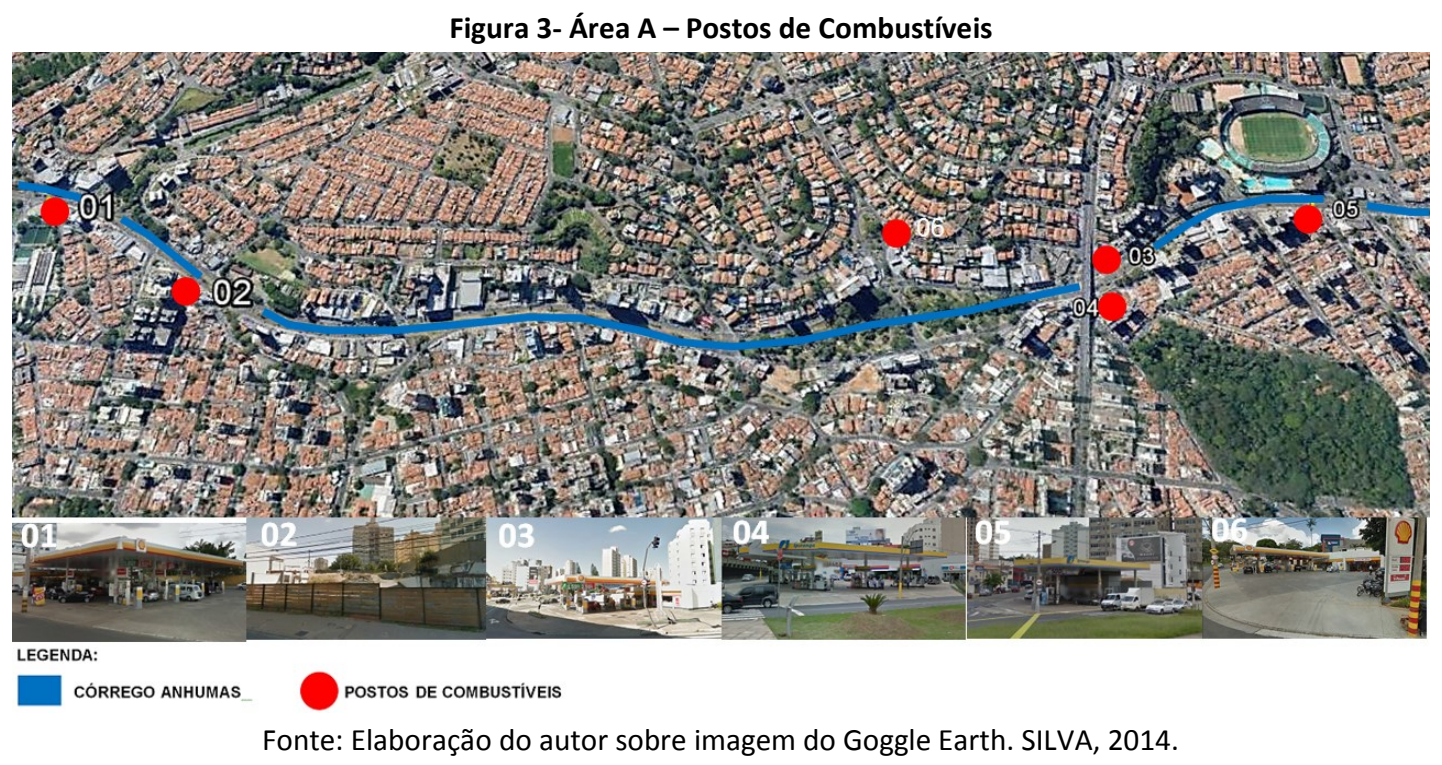

A origem da contaminação ocorreu a partir de combustíveis e solventes armazenados em tanques subterrâneos advinda do número elevado de postos, idade avançada dos tanques; inviabilizando a utilização desses recursos naturais. Segundo Trovão (2006), num derramamento de gasolina a principal preocupação é a contaminação dos aqüíferos e o manejo para o abastecimento de água para consumo humano, pois a gasolina comercializada no Brasil é misturada com álcool em proporções de 20 a 30\%. As interações entre o etanol e água, podem causar um aumento da mobilidade e solubilidade, dificultando a biodegradação natural destes compostos. A questão da contaminação crescente do meio hídrico é importante, pois a legislação urbana não controla ou veta a localização dos Postos de Combustíveis, próximos às margens dos corpos d'água. Em Campinas existem aproximadamente 93 Postos de Combustíveis, com contaminação comprovada segundo a CETESB. A maioria destes postos foi construída entre a década de 1970 e 1980. A média de vida útil de tem sido de 25 anos para tanques subterrâneos, e a maioria, supõe-se já estejam comprometidos. (ANP: 2014) A questão das águas subterrâneas é fundamental, pois, conectam os aquíferos, águas superficiais e precipitações. Por isso, os problemas operacionais dos processos de remediação, para a resolução e o restauro da potabilidade do meio hídrico, exigem vários anos para serem atingidos, e a grande maioria não atinge remediação em níveis satisfatórios. 


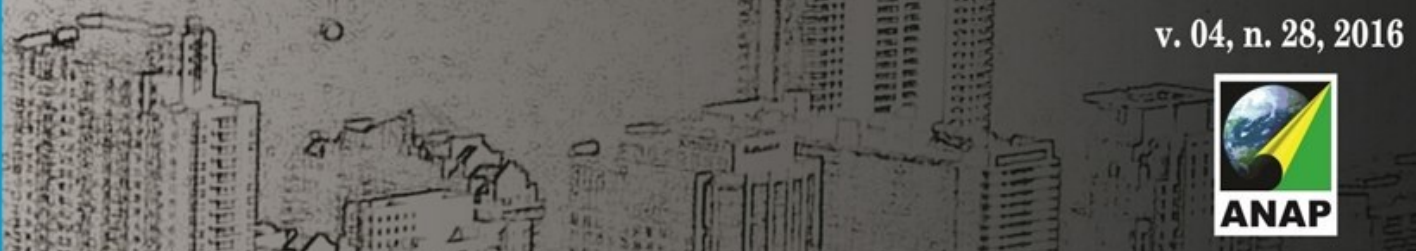

Revista Nacional de Gerenciamento de Cidades Vational Journal of Cities Manasemen

Figura 4 - Área B - Mansões Santo Antônio

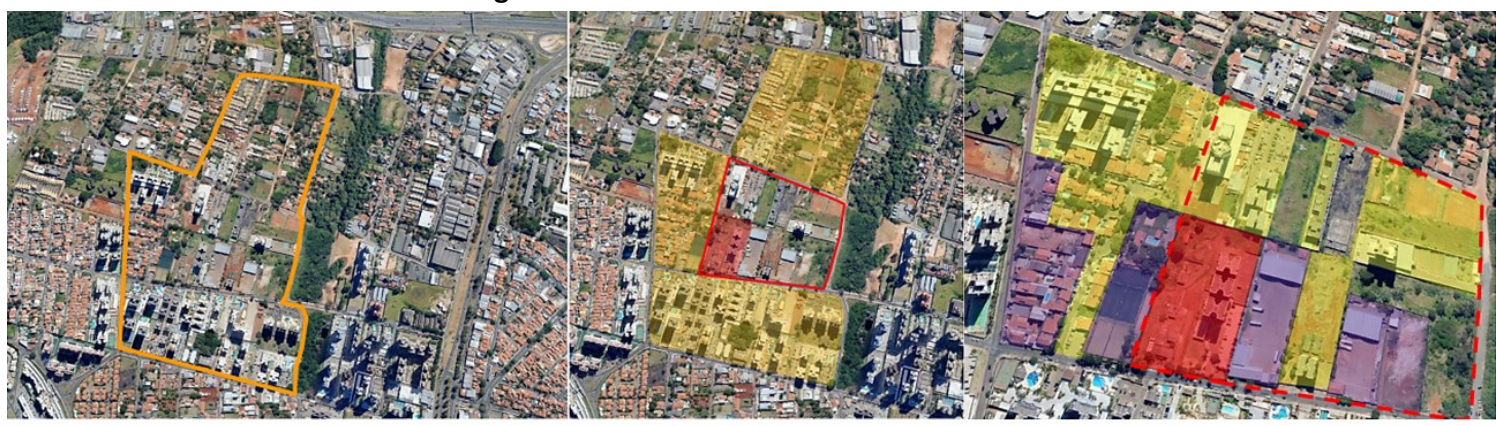

LEGENDA:

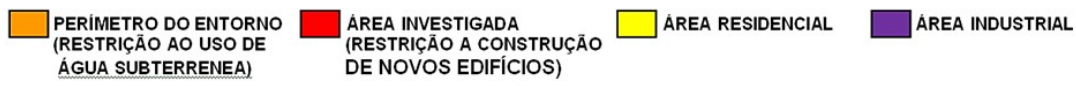

Fonte: Elaboração do autor sobre imagem do Goggle Earth. Bairro Mansões Santo Antônio, 2013.

As contaminações afetam outros locais em Campinas, como o Bairro Mansões Santo Antônio (Área B). Entre 1976 e 1996 funcionou nesta área a Proquima Produtos Químicos Ltda, uma recuperadora de solventes e produtos de limpeza feitos a partir de resíduos industriais contaminados. Em 1996 foi encerrada por ação judicial. Em 1997, a construtora Concima adquiriu o local, na época já dentro do perímetro urbano, e projetou quatro blocos de apartamentos. Das três torres construídas, apenas uma com 52 apartamentos está ocupada. Entre agosto e outubro de 2001, após intoxicação de trabalhadores e riscos de explosões, a CETESB indeferiu o empreendimento, autuou-o e determinou à Concima a isolar a área, paralisar as obras de terraplenagem, interromper a venda de apartamentos, avaliar a qualidade da água subterrânea e os níveis de explosividade destes compostos. Em setembro de 2002 (PMC, 2016), a Prefeitura suspendeu a expedição de permissões ou autorizações no movimento de terra; muro de arrimo; edificação nova; demolição total; reforma; reconstrução; poço freático ou profundo na área. $E$ ainda, qualquer utilização de águas com alguma ligação com o lençol freático, tais como fontes, poços, rios, córregos, ou nascentes, devem ser aferidas. E apesar de todas estas obrigações, o processo tem sido marcado por extrema morosidade da Concima e dos gestores públicos, com grande impacto na economia popular, envolvendo famílias que compraram a prazo apartamentos que não foram executados. 


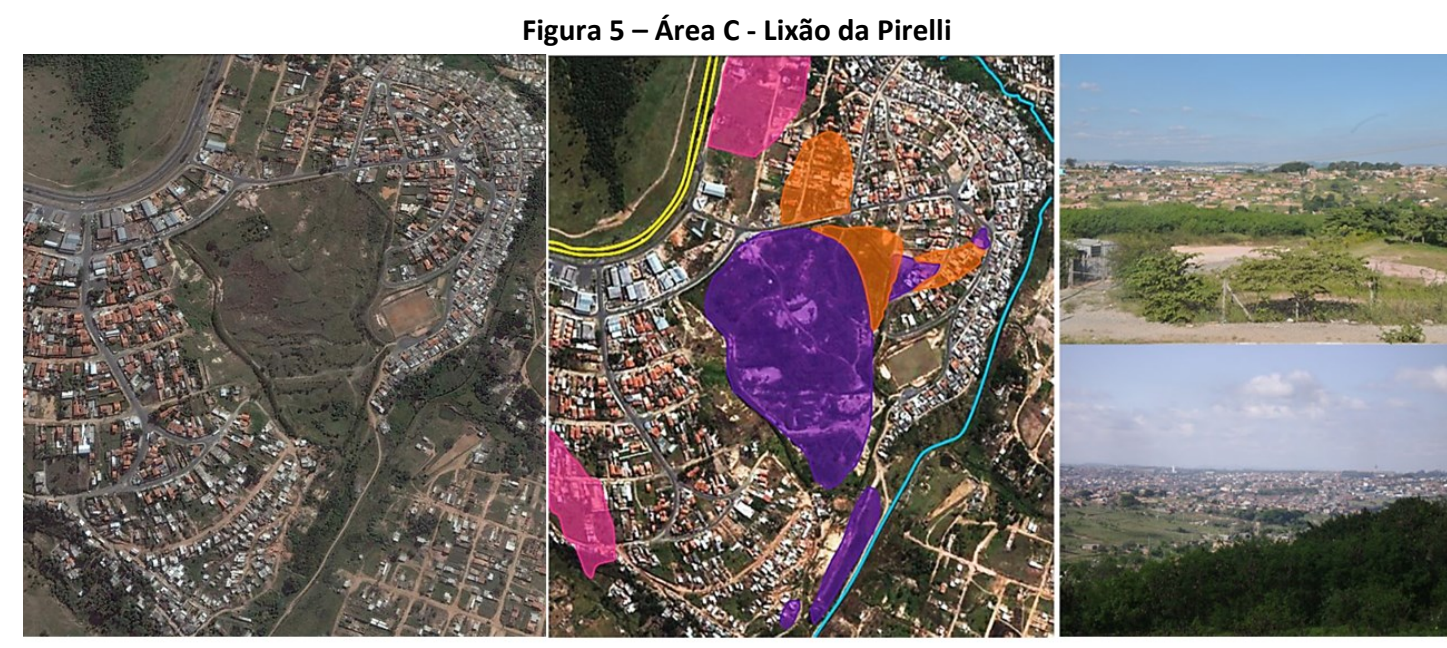

LEGENDA:

aREAS MAPEADAS

AREAS COM PROVÁVEIS DEPOSITOS ÁREAS COM RESIDUOS DEPOSITADOS E COMPROVADOS

Fonte: Elaboração do autor sobre imagem do Goggle Earth. SILVA, 2014.

A partir dos anos 1950, Campinas teve uma intensa reconfiguração e expansão urbana e industrial, com o aumento dos rejeitos municipais. A Prefeitura iniciou o seu lançamento numa área localizada no Jardim Satélite I.R.I.S ${ }^{7}$, com nascentes e córregos drenando para o Rio Capivari. O novo "lixão" recebeu diversos tipos de resíduo: doméstico, hospitalar, industrial etc. Segundo Silva (2013), o Lixão da Pirelli, configura-se como uma Zona de Sacrifício ${ }^{8}$. O antigo "Lixão da Pirelli " ", operou de 1972 a 1984, ocasionando a poluição do solo, águas superficiais e subterrâneas na área circundante. Como consequência indireta, o seu entorno foi ocupado por assentamentos informais de trabalhadores que "garimpavam" o lixo. Como tentativa de minimizar os impactos ambientais, após o seu fechamento, foi feita uma cobertura com terra argilosa sobre a massa de rejeitos e a implantação de proteção pluviométrica. Apesar disso, as dinâmicas pluviométricas e pedogênicas alteraram as estruturas do solo, espalhando os contaminantes no meio hídrico por eles atravessados. A população local, de modo precário e ilegal, utiliza - se até hoje de poços e cacimbas para solucionar a ineficiência do serviço público de saneamento, expondo-se assim aos contaminantes do antigo Lixão.

\footnotetext{
${ }^{7}$ O nome I.R.I.S. se deve à abreviação de Indústrias Reunidas Irmãos Spína S.A., proprietária da área nos anos 1950. (SILVA, 2013)

${ }^{8}$ Segundo ACSELRAD (2004) e VIÉGAS (2006) a expressão Zona de Sacrifício, surgiu nos EUA pelos movimentos de Justiça Ambiental, que relacionou a concentração espacial das contaminações ambientais a desigualdades sociais e raciais naquele país. A expressão designa as localidades com superposição de empreendimentos e instalações com danos e riscos ambientais e áreas de moradia popular. O valor da terra é mais baixo e o acesso dos moradores aos processos decisórios é mínimo, determinando a localização e destinação dos rejeitos urbanos e industriais perigosos.

${ }^{9}$ A denominação deve-se à proximidade da Pirelli Pneus, que adquiriu a unidade fabril da Dunlop Pneus em 1970 (SILVA, 2013).
} 


\section{CONCLUSÕES}

A contaminação do espaço urbano e rural é um problema complexo. No Estado de São Paulo, o mais rico e estruturado do Sudeste, a região mais desenvolvida do país, há informações disponíveis. Mas o conhecimento sobre aos casos não tem se refletido em ações equivalentes pelos gestores públicos. A ausência do poder público, se deve principalmente a ausência de estratégias, como uma legislação de uso e ocupação do solo que controle os processos de ocupação do território e também o licenciamento, o que facilitaria a fiscalização do empreendimento, com a autuação das fontes contaminadoras. A legislação poderia até mesmo dar um passo adiante, como influenciar na regressão de possíveis instrumentos fiscais, que incentivaram à instalação do empreendimento. As municipalidades têm dificuldades para organizar possíveis ações concretas, como os Planos de Contingencia que podem identificar os riscos, perigos e acidentes, vinculando-os a outras ações e meios de informação que afastem o receio e o pânico das populações residentes nestes locais. Porém, o planejamento municipal, em especial, a legislação de uso e ocupação do solo, tem atuado pontualmente e somente em casos muito graves. Os municípios deveriam ser atores chaves no processo de gestão das áreas contaminadas. Pois até mesmo, as dinâmicas deste processo, como o controle da produção, transporte, comercialização e acondicionamento, não são sistematizadas, resultando em pouca remediação. As situações vistas neste estudo, e são exemplos claramente negativos da ingerência do poder público municipal, que por falta de ações sistematizadas, não conseguem produzir ações especificas e integradas para gestão destas áreas no espaço interurbano e rural.

\section{AGRADECIMENTOS}

Os autores Ricardo Alexandre da Silva e Laura machado de Mello Bueno, agradecem a ANAP.

\section{REFERÊNCIAS}

ACSELRAD, Henry. Conflito Social e meio ambiente no Estado do Rio de Janeiro. Rio de Janeiro: Relume Dumará, 2004. 262p.

ACSELRAD, Henry. Tecnologias Sociais e Sistemas Locais de Poluição. Revista Horizontes Antropológicos, ano 12, n. 25. Porto Alegre: jan./jun. 2006. 21p. Disponível em: <http://www.scielo.br/pdf/ha/v12n25/a07v1225.pdf.> Acesso em 26 de junho de 2016.

BRAGA, Sandra Rodrigues. Água, uma questão para a geopolítica: reflexões sobre a hidrogeopolítica na Panamérica. Revista Estudos Amazônicos: Fronteiras e Territórios, v. 01. Tocantins: UFT, 2009. 24p. Disponível em <http://revista.uft.edu.br/index.php/amazonidas/article/view/14.> Acesso em 20 de julho de 2016.

BAENINGER, Rosana Aparecida. Região Metropolitana de Campinas - Expansão e Consolidação do Urbano Paulista. Campinas: NEPO/Unicamp, 2001. 28p. Disponível em: < 
https://www.researchgate.net/publication/267198747_Regiao_Metropolitana_de_Campinas_expansao_e_consolid acao_do_urbano_paulista.> Acesso em 05 de julho de 2016.

BAIRRO MANSÕES SANTO ANTÔNIO. Investigação Ambiental Detalhada e Avaliação de Risco à Saúde Humana. Campinas: PMC, 2013. 223p. Disponível em: <http://www.campinas.sp.gov.br/arquivos/meioambiente/draft_mansoes_santo_antonio.pdf.> Acesso em 14 de julho de 2016.

BRANCO, Samuel Murgel. O fenômeno Cubatão. São Paulo: Ver Curiosidades, 1984. 103p.

BUENO, Laura Machado de Melo. Sociedade Sustentável em Ambientes Saudáveis: utopia em metrópoles? IN SOUZA, Maria Adélia A. de. (Org.) A metrópole e o futuro: refletindo sobre Campinas. Campinas: Territorial, 2008. $550 \mathrm{p}$.

GUIBERLET, Jutta Cubatão. Desenvolvimento, exclusão social e degradação ambiental. São Paulo: EDUSP/FAPESP, 1996. 244p.

MOTA, Suetônio. Urbanização e meio ambiente. Rio de Janeiro: ABES, 1999. 352p.

REZENDE, Júnia Maria Passos. O Caso Shell/Cyanamid/Basf: epidemiologia e informação para o resgate de uma precaução negada. Campinas: FCM/Unicamp, 2005. 177p. Disponível em: < http://www.bibliotecadigital.unicamp.br/document/?code=vtls000366157> Acesso em 10 de abril de 2016.

RODRIGUES, Arlete Moyses. Produção e consumo do e no espaço: problemática ambiental urbana. São Paulo: Hucitec, 1998. 193p. Disponível em <http://bibliotecadigital.puc-campinas.edu.br/services/ebooks/Arlete\%20Moyses\%20Rodrigues-1.pdf.> Acesso em 15 de maio de 2016.

SINGER, Paul. Economia Política da Urbanização. São Paulo: Brasiliense - CEBRAP, 1973. 152p.

SILVA, Ricardo Alexandre da. O Processo de Expansão Urbana Recente da Região Sudoeste de Campinas - Agentes e Impactos. Campinas: PUC-Campinas, 2013. 132p. Disponível em: <http://tede.bibliotecadigital.puccampinas.edu.br:8080/jspui/bitstream/tede/110/1/Ricardo\%20Alexandre\%20da\%20Silva.pdf> Acesso em 08 de abril de 2016.

SOARES, Jorge Luís Nascimento. Degradação de Solos Cultivados ao longo de uma Seqüência Topográfica, em Bariri (SP). Campinas: FEAGRI/Unicamp, 2001. 157p. Disponível em: < http://www.bibliotecadigital.unicamp.br/document/?code=vtls000243466\&opt=4.> Acesso em 20 de abril de 2016.

SUASSUNA, Karen. Contaminação em Paulínia por Aldrin, Dieldrin, Endrin e outros compostos tóxicos produzidos e descartados pela Shell do Brasil S.A. In Campanha de Substâncias e Tecnologias Tóxicas. São Paulo: Greenpeace, 2001. Disponível em: <www.conjur.com.br/dl/relatorio-shell-greenpeace.pdf.> Acesso em 10 de julho de 2016.

TROVÃO, Renata Silva. Análise Ambiental de Solos e Águas Subterrâneas Contaminadas com Gasolina: Estudo de Caso no Município de Guarulhos - SP. São Paulo: Poli/USP, 2006. 224p. Disponível em: < http://www.teses.usp.br/teses/disponiveis/3/3134/tde-09082007-183630/pt-br.php> Acesso em 12 fevereiro de 2016.

VIÉGAS, Rodrigo Nuñez. Desigualdade Ambiental e “Zonas de Sacrifício". Rio de Janeiro, PPGSA/IFCS - UFRJ, 2006. 24p. Disponível em: <http://livros01.livrosgratis.com.br/ea000392.pdf> Acesso em 12 de junho de 2016.

VILLAÇA, Flávio. Espaço intra-urbano no Brasil. São Paulo Studio Nobel/FAPESP, 1998. 373p.

\section{SÍTIOS ACESSADOS}

CETESB. Disponível em: <http://www.cetesb.sp.gov.br/.> Acesso em 25 de julho de 2016. 
A questão ambiental. Disponível em: <http://emergenciasquimicas.cetesb.sp.gov.br/tipos-deacidentes/postos-de-combustiveis/a-questao-ambiental/.> Acesso em 25 de julho de 2016.

: Central Técnica de Tratamento e Disposição de Resíduos Industriais (CETRIN). Disponível em: <http://areascontaminadas.cetesb.sp.gov.br/aterros-industriais-mantovani-e-cetrin/.> Acesso em 25 de julho de 2016. Acesso em 25 de julho de 2016.

: Manual de Gerenciamento de Áreas Contaminadas - 2013. Disponível em: <http://www.cetesb.sp.gov.br/areas-contaminadas/manual-de-gerenciamento-de-ACs/7-manual.> Acesso em 25 de julho de 2016.

: Relação de áreas Contaminadas e Reabilitadas no Estado de São Paulo. Disponível em: $\overline{<h t t p: / / w w w . c e t e s b . s p . g o v . b r / u s e r f i l e s / f i l e / a r e a s-c o n t a m i n a d a s / 2013 / m u n i c i p i o s . p d f>. ~ A c e s s o ~ e m ~} 25$ de julho de 2016. Acesso em 25 de julho de 2016.

\footnotetext{
Texto explicativo sobre áreas Contaminadas. Disponível em: $\overline{\langle h t t p: / / w w w . c e t e s b . s p . g o v . b r / u s e r f i l e s / f i l e / a r e a s-c o n t a m i n a d a s / 2013 / t e x t o-e x p l i c a t i v o . p d f .>~ A c e s s o ~ e m ~} 10 \mathrm{de}$ agosto de 2016.
}

GTZ - Deutsche Gesellschaft Für Internationale Zusammenarbei. Disponível em: http://www.giz.de/en/. Acesso em 25 de julho de 2016.

IBGE. Classificação de Atividades Econômicas - 2010. Brasília, 2014. Disponível em: < http://www.ibge.com.br/home/estatistica/economia/classificacoes/cnae2.0/cnae2.0.pdf>. Acesso em 25 de julho de 2016.

INEA. Cadastro de áreas contaminadas por produtos químicos - 2015. Disponível em: <http://www.inea.rj.gov.br/.> Acesso em 26 de julho de 2016

PMC. Decreto no 18.669 de 13 de março de 2015 (Revisão do Decreto municipal, de no 14.091/02). Disponível em: <http://www.campinas.sp.gov.br/uploads/pdf/815114133.pdf.> Acesso em 15 de julho de 2016.

PETROBRÁS. Refinaria de Paulínia - Informações Gerais. Disponível em: <http://www.petrobras.com.br/pt/nossasatividades/principais-operacoes/refinarias/refinaria-de-paulinia-replan.htm.> Acesso em 4 de agosto de 2016. 